\title{
Comparison of foetal metabolic differentiation in three cattle muscles
}

\author{
Hélène Gagnière, Brigitte Picard*, Catherine Jurie, Yves Geay
}

\begin{abstract}
Laboratoire croissance et métabolismes des herbivores, UR croissance musculaire, Inra Clermont-Ferrand/Theix, 63122 Saint-Genès-Champanelle, France
\end{abstract}

(Received 18 May 1998; accepted 2 December 1998)

\begin{abstract}
Metabolic differentiation of Semitendinosus (ST), Cutaneus trunci (CT) and Masseter (MA) in cattle foetuses aged from 110 to 260 days was studied by measuring isocitrate dehydrogenase (ICDH, oxidative) and lactate dehydrogenase (LDH, glycolytic) activities. The five LDH isoenzymes were separated by electrophoresis and assayed by densitometry. ICDH activity increased from 210 days onwards in the three muscles but more intensively in MA (oxidative). LDH activity increased from 170 days onwards in ST, 180 days onwards in CT and only from 210 days onwards in MA and was higher in the glycolytic muscles (ST and CT). The proportion of the LDH-M subunit increased during foetal life in glycolytic muscles. At 110 days, it was higher in CT, intermediate in ST and lower in MA. These results show that 1) metabolic differentiation of bovine muscle begins during the last third of foetal life and 2) the proportion of the LDH-M subunit seems to be related to the contractile type of adult muscle from the first stages of foetal life. (C Inra/Elsevier, Paris.
\end{abstract}

muscle / differentiation / metabolism / cattle / foetus

Résumé - Comparaison de la différenciation fotale métabolique chez trois muscles de bovin. La différenciation métabolique des muscles Semitendinosus (ST), Cutaneus trunci (CT) et Masseter (MA) est étudiée chez des foetus bovins âgés de 110 à $260 \mathrm{j}$. Les activités de l'isocitrate déshydrogénase (ICDH, oxydative) et de la lactate déshydrogénase ( $\mathrm{LDH}$, glycolytique) sont mesurées. Les cinq isoformes de la $\mathrm{LDH}$ sont séparées par électrophorèse et quantifiées par densitomètrie. L'activité ICDH augmente à partir de $210 \mathrm{j}$ dans les trois muscles, mais de manière plus intense dans le MA (oxydatif). L'activité LDH augmente à partir de $170 \mathrm{j}$ dans le $\mathrm{ST}, 180 \mathrm{j}$ dans le CT et seulement à partir de ${ }^{p}$ $210 \mathrm{j}$ dans le MA. À $210 \mathrm{j}$, le ST est le plus glycolytique, le CT intermédiaire, et le MA le moins glycolytique. La proportion de LDH-M augmente tout au long de la vie fotale dans les muscles glycolytiques. À partir de $110 \mathrm{j}$, elle est plus importante dans le CT, intermédiaire dans le ST et plus faible dans le MA. Ces résultats montrent que 1) la différenciation métabolique des muscles de bovins commence durant le dernier tiers de vie fotale et 2) la proportion de LDH-M semble liée au type contractile dès le début de la vie fơtale. ( Inra/Elsevier, Paris.

muscle / différenciation / métabolisme / bovin / fotus

\footnotetext{
* Correspondence and reprints

E-mail: picard@clermont.inra.fr
} 


\section{INTRODUCTION}

Skeletal muscle is composed of three main fibre types (I, IIA, IIB), differing by their contractile and metabolic properties. In bovine, these different fibre types appear during foetal life. Previous studies on contractile differentiation have shown that two populations of cells are involved in foetal development of skeletal muscle in cattle [21, 23]. A first generation of cells appears at 39 days of foetal life and matures into type I fibres at 210 days in all studied muscles. The second generation, composed of smaller cells, starts between 90 and 120 days, depending on the muscle. It gives rise to IIA and IIB fast fibres in fast adult muscles and some type I fibres in slow muscles. At 210 days, the second generation is composed of two categories of cells: fast type II fibres which still express embryonic and foetal myosin heavy chain (MHC) and some type IIC fibres expressing slow and fast MHCs simultaneously.

In several species (pig, chicken and rabbit), it has been shown that the energetic metabolism is mainly oxidative during foetal life, whereas glycolytic metabolism takes place during the first weeks after birth [3, $4,6]$. Cattle, a species whose contractile properties at birth are more mature than those encountered in other species [21], are also more advanced in their metabolic differentiation. Thus, glycolytic activity increases more quickly than the oxidative one during foetal life [1]. Oxidative metabolism decreases between 1 and 12 months, whereas glycolytic metabolism keeps on increasing steadily with age [15].

Metabolic differentiation occurs at different times between muscles. In the rabbit, muscles involved in posture acquire their maximum capacity very quickly after birth, whereas those involved in mobility gradually acquire their adult profile during postnatal life [11]. Anaerobic glycolytic activities increase steadily in rabbit fast muscles until adulthood, whereas they remain stable in slow muscles. Aerobic oxidative metabolism takes place quickly after birth in both the slow and fast muscles of the chicken, pig and rabbit. It increases quickly after birth in slow muscles and then decreases until adulthood, whereas it decreases steadily in fast muscles [4, 11, 17]. A full description of muscle metabolic differentiation during foetal life in cattle is still lacking. Therefore, the aim of the present study is to investigate the variability in metabolic differentiation of three foetal cattle muscles exhibiting different contractile and metabolic properties in adult animals: the Cutaneus trunci (CT), made up of fast type IIA and IIB fibres [20]; the Masseter (MA), which in adult cattle contains only type I fibres [26]; the Semitendinosus (ST), which is a mixed muscle composed of an average of $15 \% \mathrm{I}$, $45 \%$ IIA and $50 \%$ IIB fibres $[14,28]$. For this purpose, we monitored isocitrate dehydrogenase (ICDH) and lactate dehydrogenase (LDH) activities, indicative of aerobic oxidative and anaerobic glycolytic metabolism, respectively, and the LDH isozyme pattern at different stages of foetal life.

\section{MATERIALS AND METHODS}

\subsection{Muscle sampling}

Twenty-three foetuses aged 110, 130, 150, $170,180,210,230$ and 260 days were obtained by artificial insemination of Charolais $\times$ Salers crossbreed heifers with charolais bull sperm. After slaughter of pregnant mothers, three muscles differing in their adult contractile and metabolic characteristics were excised from two or four foetuses of each age: the Semitendinosus muscle (ST) (mixed muscle), the Cutaneus trunci muscle (CT) (fast glycolytic muscle) and the Masseter muscle (MA) (slow oxidative muscle). They were immediately frozen in liquid nitrogen and stored at $-80^{\circ} \mathrm{C}$ until analysed.

\subsection{Enzymatic activities}

The muscle samples $(200 \mathrm{mg})$ were ground and homogenized in $4 \mathrm{~mL}$ of $140 \mathrm{mmol} \cdot \mathrm{L}^{-1}$ sucrose, $50 \mathrm{mmol} \cdot \mathrm{L}^{-1}$ triethanolamine buffer $\mathrm{pH}$ 
7.5 , and centrifuged at $6000 \mathrm{~g}$ for $15 \mathrm{~min}$ at $4{ }^{\circ} \mathrm{C}$. The enzyme activities were measured in the supernatant. Aerobic oxidative metabolism was studied by measuring isocitrate dehydrogenase (EC 1.1 .1 .42 ) activity according to Briand et al. [9]. This activity was measured by following the reduction of nicotinamide adenine dinucleotide phosphate (NADP) at $340 \mathrm{~nm}$ in the reaction medium: $\mathrm{Na}_{2} \mathrm{HPO}_{4} 38.8 \mathrm{mmol} \cdot \mathrm{L}^{-1}, \mathrm{MnCl}_{2} 0.5$ mmol. $\mathrm{L}^{-1}$, Triton X-100 $0.05 \%$, NADP 0.36 $\mathrm{mmol} \cdot \mathrm{L}^{-1}$, isocitrate $1.38 \mathrm{mmol} \cdot \mathrm{L}^{-1} \mathrm{pH} 7.5$. Anaerobic glycolytic metabolism was characterized by measuring lactate dehydrogenase (EC 1. 1. 1.27) activity in the reaction from pyruvate to lactate. This activity was measured by following the disappearance of the reduced form of nicotinamide adenine dinucleotide (NADH) at $340 \mathrm{~nm}$ in the reaction medium: triethanolamine $50 \mathrm{mmol} \cdot \mathrm{L}^{-1}$, EDTA $5 \mathrm{mmol} \cdot \mathrm{L}^{-1}$, $\mathrm{NADH}_{2} 0.34 \mathrm{mmol} \cdot \mathrm{L}^{-1}, \mathrm{pH} 7.5$, sodium pyruvate $2 \mathrm{mmol} \cdot \mathrm{L}^{-1}$ [2]. The enzyme activities were expressed in $\mu \mathrm{mol} \mathrm{min}^{-1} \cdot \mathrm{g}^{-1}$ of muscle.

\subsection{Lactate dehydrogenase isozyme pattern}

The LDH isozymes were separated using a Sebia kit (Hydragel ISO-LDH). Three microlitres of supernatant, used for the determination of enzyme activities, were loaded onto agarose gels. Five $\mathrm{LDH}$ isozymes $\left(\mathrm{M}_{4}, \mathrm{M}_{3} \mathrm{H}, \mathrm{M}_{2} \mathrm{H}_{2}, \mathrm{MH}_{3}\right.$ and $\mathrm{H}_{4}$ ) were separated by electrophoresis under nondenaturing conditions for $60 \mathrm{~min}$ at $10^{\circ} \mathrm{C}$. The LDH activity was revealed as follows:

$$
\begin{gathered}
\text { lactate }+\mathrm{NAD}^{+} \rightarrow \text { pyruvate }+\mathrm{NADH}+\mathrm{H}^{+} \\
\mathrm{NADH}+\mathrm{H}^{+} \mathrm{PMS} \rightarrow \mathrm{PMSH}_{2}+\mathrm{NAD}^{+} \\
\mathrm{PMSH}_{2}+\mathrm{NBT} \rightarrow \mathrm{NBT}-\text { formazan }+\mathrm{PMS}^{\mathrm{NB}}
\end{gathered}
$$

The gels were analysed using a scanning densitometer (Hoefer Scientific) and the proportion of each isozyme was calculated using densitometry software (GSW 365 Hoefer Scientific). The proportion of LDH-M subunits was calculated according to Thorling and Jensen [27] as:

$$
\begin{gathered}
\mathrm{LDH}-\mathrm{M}(\%)= \\
\mathrm{M}_{4}+3 / 4 \mathrm{M}_{3} \mathrm{H}+1 / 2 \mathrm{M}_{2} \mathrm{H}_{2}+1 / 4 \mathrm{MH}_{3}
\end{gathered}
$$

\subsection{Statistical analysis}

The statistical analyses of the resulting data were performed with a SAS package [24], using the general linear models procedure (GLM). Least square estimates appropriate to testing the impact of age and muscle type were obtained in a linear model on the pooled muscle data.

\section{RESULTS}

\subsection{Foetal development of the oxidative and glycolytic metabolisms in three muscles of cattle foetuses}

The ICDH activity measured in the three cattle muscles was weak and stable between 110 and 210 days (figure $1 a$ ). It increased significantly from 210 days in ST $(P<0.05)$ and $\mathrm{CT}(P<0.01)$, and from 230 days $(P<0.001)$ in MA.

The LDH activity remained stable between 110 and 170 days in the three muscles (figure 1b). It increased significantly from 170 days in ST $(P<0.01), 180$ days in CT $(P<0.01)$ and 210 days in MA $(P<0.01)$.

The electrophoretic separation under nondenaturing conditions of the five LDH isozymes showed them all to be present in the three muscles from 110 to 260 days. However, their distribution differed according to the muscle type (figure 2). The percentage of $\mathrm{M}_{4}$ increased significantly from 110 to 260 days in ST $(P<0.001)$ and in CT $(P<0.001)$. In MA it remained relatively stable during this period. The proportions of $\mathrm{M}_{3} \mathrm{H}$ tended to increase in ST and CT. The $\mathrm{M}_{2} \mathrm{H}_{2}$ and $\mathrm{MH}_{3}$ isozymes represented the greater part of the LDH activity in the three muscles at 110 days. Their proportions significantly decreased up to 260 days in ST and CT muscles but not in MA. $\mathrm{H}_{4}$ decreased significantly in these two muscles $(P<0.001)$. The proportion of all five isozymes remained quite stable during foetal life in MA muscle. Thus, the proportion of LDH-M subunits increased very significantly $(P<0.001)$ from 50.3 to $74.3 \%$ in CT and from 46.6 to $71.7 \%$ in ST between 110 and 260 days, whereas it weakly changed in MA muscle (figure 2f). 
a

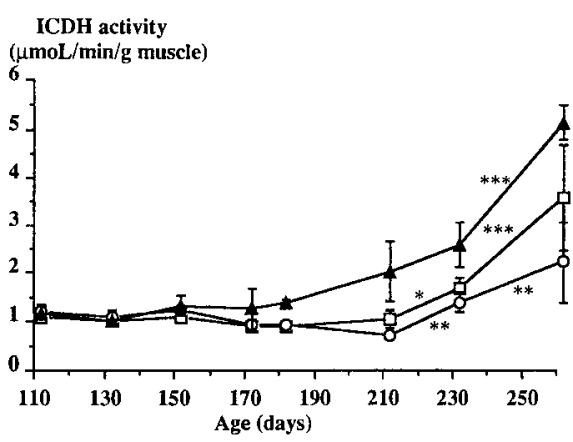

b

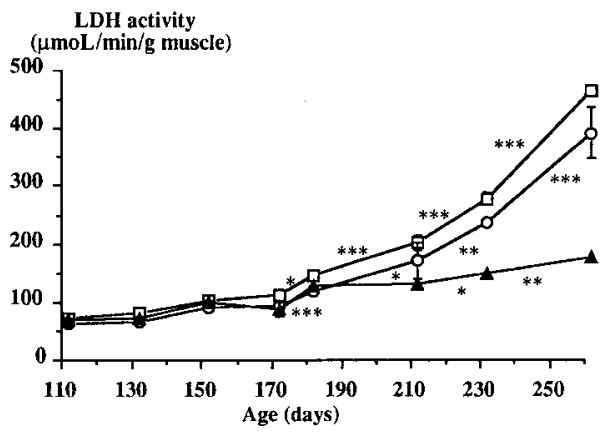

Figure 1. Development of enzymatic activity: (a) isocitrate dehydrogenase (ICDH) and (b) lactate dehydrogenase (LDH) in Semitendinosus $\square$, Cutaneus trunci $\mathrm{O}$, Masseter $\mathbf{A}$ muscles of cattle foetuses aged 110-260 days. Values are mean for $2-4$ animals $\pm \mathrm{SD}(* P<0.05, * * P<0.01$, *** $P<0.001$ ).

\subsection{Comparison of the three muscles}

The ICDH activity was not significantly different between the three muscles before 180 days. Thereafter, MA was the most oxidative muscle $(P<0.001)$, ST displayed an intermediate ICDH activity and CT exhibited the lowest ICDH activity (figure la). At 260 days, ICDH activity reached 5 , 3.43 and $2.07 \mu \mathrm{mol} \cdot \mathrm{min}^{-1} \cdot \mathrm{g}^{-1}$ of muscle in MA, ST and CT muscle, respectively. The difference was only significant for MA $(P<0.01)$.

Significant differences in LDH activity between the three muscles were observed: from 170 days onwards, ST was the most glycolytic, CT intermediate and MA the least glycolytic (figure 1 b) . At 260 days, the LDH activity reached $454.4,380.2$ and $165.3 \mu \mathrm{mol} \cdot \mathrm{min}^{-1} \cdot \mathrm{g}^{-1}$ of muscle in ST, CT and MA muscle, respectively. The difference was only significant for MA $(P<0.001)$.

The percentage of $\mathrm{M}_{2} \mathrm{H}_{2}$ was significantly higher in MA $(P<0.01)$ than in CT and ST from 150 days onwards. The proportions of $\mathrm{MH}_{3}$ and $\mathrm{H}_{4}$ isozymes were also significantly higher in MA $(P<0.001$ and $P<0.01$, respectively) than in CT and ST from 150 and 230 days, respectively. On the contrary, the proportion of $\mathrm{M}_{4}$ was the lowest in MA $(P<0.01)$. The percentages of $\mathrm{M}_{3} \mathrm{H}$ and $\mathrm{M}_{4}$ isozymes were higher in CT than in ST muscles (from 110 to 210 days $P<0.001$ ), whereas the opposite was found for $\mathrm{MH}_{3}$ and $\mathrm{H}_{4}(P<0.001$ from 110 to 210 days). The percentage of LDH-M subunits (figure $2 f$ ) was significantly lower in MA than in the other muscles from 210 days onwards $(P<0.001)$. It was significantly higher in CT than in ST. These differences were significant at 130,170 and 210 days $(P<0.001)$, but were not different at 230 and 260 days in these muscles.

\subsection{Relations between LDH activity and isozymes}

As a whole, activities of the ICDH and LDH metabolic enzymes were discriminant between muscles only after 180 days of gestation, whereas an LDH isozyme pattern allowed a distinction between muscles from 110 days onwards. In the two glycolytic muscles the increase in LDH activity was accompanied by an increase in the proportions of $\mathrm{M}_{3} \mathrm{H}$ and $\mathrm{M}_{4}$, and consequently of the LDH-M subunit. On the contrary, the proportions of $\mathrm{H}_{4}, \mathrm{MH}_{3}$ and $\mathrm{M}_{2} \mathrm{H}_{2}$ decreased. In the oxidative muscle (MA) the evolution of isozymes was the opposite. 
a

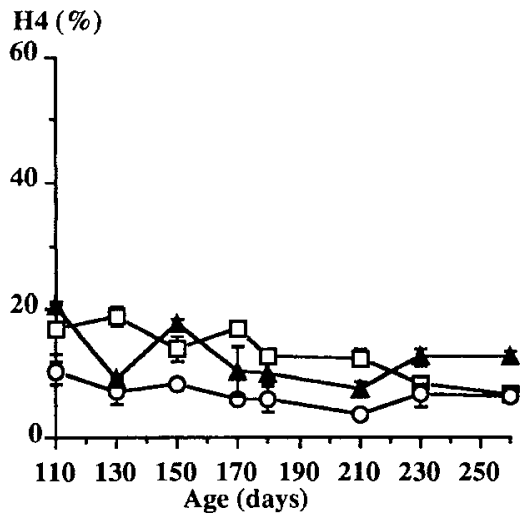

c

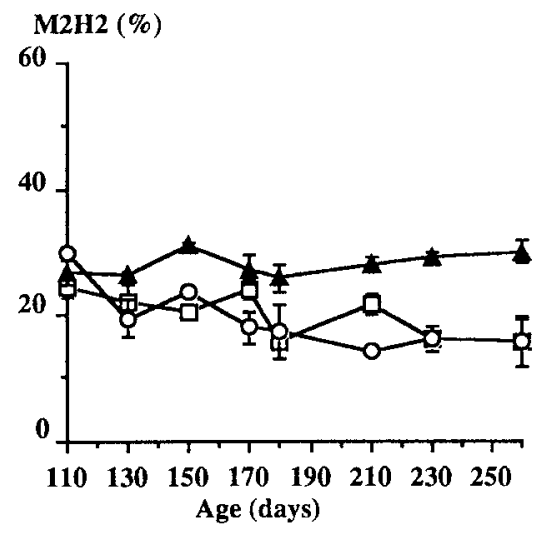

e

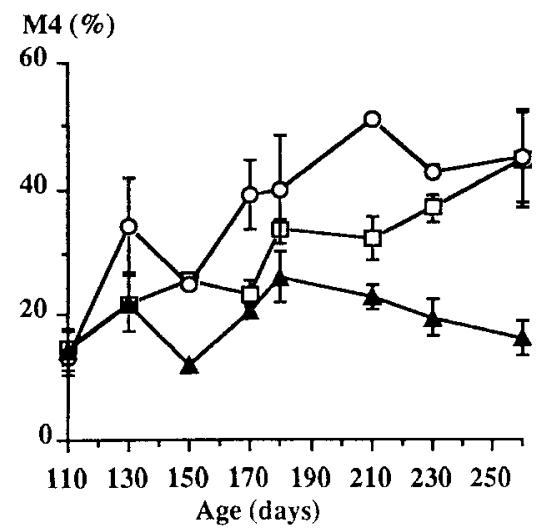

$\mathbf{b}$

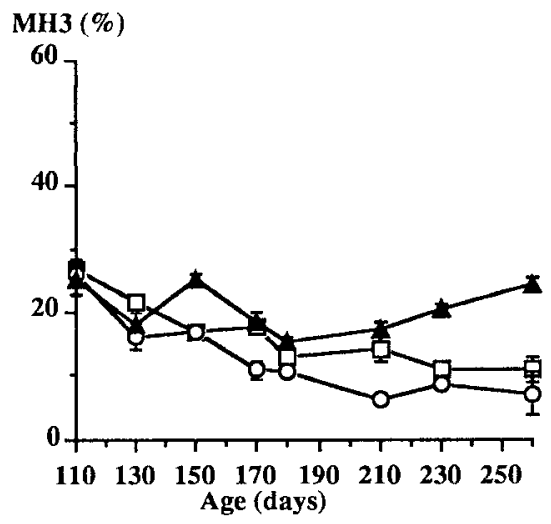

d

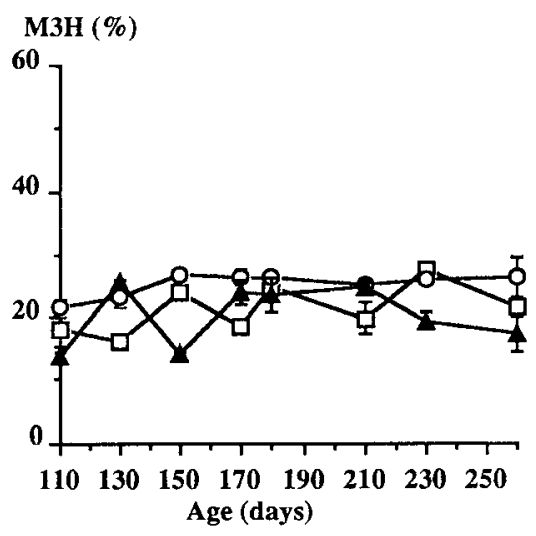

LDH-M sub-unit (\%)

100

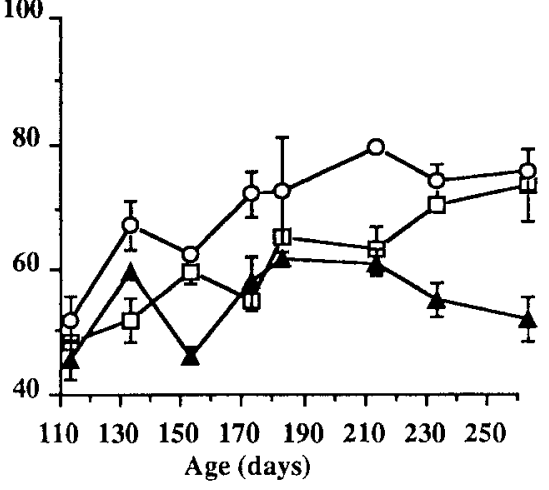

Figure 2. Development of different lactate dehydrogenase isozymes and LDH-M subunits in Semitendinosus $\square$, Cutaneus trunci $\mathrm{O}$, Masseter $\triangle$ muscles of cattle foetuses aged 110-260 days: (a) $\mathrm{H}_{4}$, (b) $\mathrm{MH}_{3}$, (c) $\mathrm{M}_{2} \mathrm{H}_{2}$, (d) $\mathrm{M}_{3} \mathrm{H}$, (e) $\mathrm{M}_{4}$, (f) LDH-M subunits. Values are mean for $2-4$ animals $\pm \mathrm{SD}$. 


\section{DISCUSSION}

\subsection{Development of enzymatic activities during foetal life}

The results obtained show that the differentiation of energetic metabolism in foetal cattle muscle takes place during the last third of foetal life. Thus, during this period, ICDH and LDH activities increased significantly. ICDH activity increased from 210 days and this increase was more important in MA than in ST and CT muscles. LDH activity increased from 170 and 180 days in the ST and CT muscles, respectively. This increase was more important in these muscles than in MA. Therefore, the energetic metabolism of cattle muscle differentiates during the end of foetal growth, in contrast to rabbit and chicken where metabolic differentiation occurs after birth $[4,6,8,11]$. Our results show that cattle is relatively mature at birth with regard to metabolic characteristics, as previously reported for contractile characteristics [21, 23]. However, the metabolic differentiation seems to occur later than the contractile one which has been reported to take place principally during the first two thirds of gestation [21,23].

\subsection{Comparison of muscles}

As previously reported for contractile differentiation [21], metabolic differentiation occurs at different times according to the muscle type and its adult function. Thus, in MA, a muscle containing only slowtwitch oxidative fibres in the adult $[21,22$, 26], oxidative metabolism differentiated earlier than that of ST, which is a mixed muscle composed of half type IIB fibres in adult cattle $[14,28]$ and CT, which is a fast-twitch muscle containing only fast IIB and IIA fibres in adult bovine [20]. Glycolytic metabolism increased earlier in ST and CT than in MA muscle. At birth, the contractile and metabolic differentiation were not over in MA. Indeed, MA still contained $40-50 \%$ of type IIC fibres at birth, and the proportion of type I fibres and ICDH activity still increased to reach $99 \%$ and $8.7 \mu \mathrm{mol} \cdot \mathrm{min}^{-1} \cdot \mathrm{g}^{-1}$ of muscle at 6 months of age, respectively [22]. At birth, CT muscle contained $95 \%$ of type II fibres [21], whereas ST muscle was composed of three adult fibre types and some type IIC fibres. The oxidative metabolism seems to reach a maximum around birth, since it was higher at 260 days of gestation than at 1 month postnatal [14]. These results agree with those obtained in rabbit, chicken and pig muscles $[4,17]$. On the contrary, glycolytic metabolism still increases after birth in fast cattle muscles, as observed in chicken [4], rabbit [11] and pig [17].

\section{3. $\mathrm{LDH}$ isozyme pattern}

Five LDH isoenzymes are present from 110 days of gestation in cattle skeletal muscle. The distribution of the isozymes gradually changed during foetal growth. The LDH-M subunit, in particular the $\mathbf{M}_{4}$ isozyme, was predominant from 130 days in ST and CT muscles. At 260 days these muscles contained more than $70 \%$ of the LDH-M subunit. Thus, the $\mathrm{M}_{4}$ isozyme was the most abundant isoform in the fast foetal skeletal muscles of cattle, as already shown in the human [12] and in the mouse [18]. However, in less mature species such as the pig and rabbit, $\mathrm{H}_{4}$ represents the greater part of LDH isozymes of foetal skeletal muscle at birth $[13,15]$ and decreases postnatally. Changes in the isozymic profile of LDH were muscle type dependent. Thus, in MA, which is a slow oxidative muscle in the adult, the proportion of the LDH-M subunit was relatively stable throughout gestation. On the contrary, the percentage of the LDH$M$ subunit increased in ST and CT (glycolytic muscles) during foetal growth. Previous postnatal studies carried out in the guinea pig [19], rabbit [11] and sheep [10] muscles have shown that the LDH isozyme pattern is correlated with fibre type. Thus, muscles containing numerous fast-twitch 
glycolytic fibres display a high proportion of $\mathrm{M}_{4}$ isozymes, whereas those composed mainly of slow-twitch oxidative fibres present a low percentage of $\mathrm{H}_{4}$ and $\mathrm{MH}_{3}$ isozymes. However, Leberer and Pette [16] showed on isolated rabbit muscle fibres that the correlation is not strict. The present study shows that this relationship exists from the early foetal stage in cattle. Indeed, muscles composed primarily of slow fibres, such as MA, contained fewer LDH-M subunits than those composed mainly of fast glycolytic fibres, such as CT and ST.

\subsection{Relation between LDH activity and isozymes}

It is worth noting that the isozyme pattern makes it possible to discriminate between muscle types as early as 130 days, whereas the enzyme activities allow a distinction between muscles only during the last third of gestation. Therefore, these results suggest that the isozyme differentiation takes place before differences in the LDH enzyme activity can be detected. The increase in LDH activity is associated with an increase in $\mathrm{M}_{4}$ isozymes, and in the LDH$M$ subunit. This suggests a relationship between this isoform and the activity which is already established during foetal life. Such a relationship between the percentage of LDH-M and LDH activity development has also been observed from birth to puberty in rats [5], guinea pigs [7] and rabbits [11]. Also, studies on the effects of chronic stimulation on fast-twitch rabbit muscles show that it induces a decrease in LDH activity correlated with a transition from LDH-M to LDH-H subunits [25].

\section{CONCLUSION}

Metabolic differentiation begins during the last third of gestation in cattle muscle. The metabolic differences observed between the three adult cattle muscles are already manifest during foetal life. In the slow muscles, such as MA, the ICDH activity increased earlier than that of fast muscles such as CT and ST. In contrast, the LDH activity increased earlier than that of MA. Moreover, the percentage of LDH-M subunits seems to be related to contractile type of cattle muscle from the second third of gestation.

\section{ACKNOWLEDGEMENTS}

We thank Rt Jailler for animal management and Rd Jailler for statistical analysis.

\section{REFERENCES}

[1] Ansay M., Développement biochimique du muscle de fœ tus bovin. III. - Enzymes et différenciation, Ann. Biol. Anim. Biochem. Biophys. 14 (1974) 105-116.

[2] Ansay M., Individualité musculaire chez le bovin : étude de l'équipement enzymatique de quelques muscles, Ann. Biol. Anim. Biochem. Biophys. 14 (1974) 471-486.

[3] Ashmore C.R., Addis P.B., Doerr L., Development of muscle fibres in the foetal pig, J. Anim. Sci. 36 (1973) 1088-1093.

[4] Bacou F., Vigneron P., Évolution périnatale des voies métaboliques glycolytique et oxydative de divers types de muscles squelettiques du lapin et du poulet, Ann. Biol. Anim. Biochem. Biophys. 16 (1976) 675-686.

[5] Baldwin K.M., Hooken A.M., Campbell P.J., Lewis R.E., Enzyme changes in neonatal skeletal muscle: effect of thyroïd deficiency, Am. J. Physiol. 235 (1978) 97-102.

[6] Bass A., Lusch G., Pette D., Postnatal differentiation of enzyme activity pattern of energy-supplying metabolism in slow (red) and fast (white) muscles of chicken, Eur. J. Biochem. 13 (1970) 289-292.

[7] Beaune B., Fellman N., Villié F., Marcollet M., Coudert J., Effects of orchiectomy on EDL muscle ultrastructure and energy-supplying enzymes in the growing guinea-pig, Am. J. Physiol. 266 (1994) 143-148.

[8] Briand M., Briand Y., Metabolic and contractile properties of rabbit muscles: a statistical approach, Comp. Biochem. Physiol. 85B (1986) $481-485$.

[9] Briand M., Talmant A., Briand Y., Monin G., Durand R., Metabolic types of muscles in the sheep: I. Myosin ATPase, glycolytic and mitochondrial enzyme activities, Eur. J. Appl. Physiol. 46 (1981) 347-358. 
[10] Briand M., Talmant A., Briand Y., Monin G., Durand R., Metabolic types of muscles in the sheep: II. Lactate dehydrogenase activity and LDH isoenzyme distribution, Eur. J. Appl. Physiol. 46 (1981) 359-365.

[11] Briand M., Boissonnet G., Laplace-Marieze V., Briand Y., Metabolic and contractile differentiation of rabbit muscles during growth, Int. J. Biochem. 25 (1993) 1881-1887.

[12] Clausen J., Hustrulid R., The foetal development of lactate dehydrogenase isoenzymes, glucose6phosphate dehydrogenase and 6-phosphogluconate dehydrogenase from human striated muscle, Biochem. J. 111 (1969) 219-224.

[13] Fieldhouse B., Masters C.J., Developmental redistributions of porcine lactate dehydrogenase, Biochim. Biophys. Acta 118 (1966) 538-548.

[14] Jurie C., Robelin J., Picard B., Geay Y., Postnatal changes in the biological characteristics of Semitendinosus muscle in male limousin cattle, Meat Sci. 4 I (1995) 125-135.

[15] Laplace-Marieze V., Briand M., Badaoui S., Dadet M.H., Briand Y., Expression of lactic dehydrogenase isoenzymes in rabbit muscle during development, Int. J. Biochem. 26 (1994) 491-495.

[16] Leberer E., Pette D., Lactate dehydrogenase isozymes in type I, IIA and IIB fibres of rabbit skeletal muscles, Histochemistry 80 (1984) 295-298.

[17] Lefaucheur L., Vigneron P., Post-natal changes in some histochemical and enzymatic characteristics of three pig muscles, Meat Sci. 16 (1986) 199-216.

[18] Markert C.L., Ursprung H., The ontogeny of isozyme patterns of lactate dehydrogenase in the mouse, Dev. Biol. 5 (1962) 363-381.

[19] Peter J.B., Sawaki S., Barnard R.J., Edgerton V.R., Gillespie C.A., Lactate dehydrogenase isoen- zymes: distribution in fast-twitch red, fast-twitch white, and slow-twitch intermediate fibres of guinea-pig skeletal muscle, Arch. Biochem. Biophys. 144 (1971) 304-307.

[20] Picard B., Léger J.O.C., Robelin J., Quantitative determination of type I MHC in bovine muscle with monoclonal antibodies, Meat Sci. 36 (1994) 333-345

[21] Picard B., Robelin J., Pons F., Geay Y., Comparison of the foetal development of fibre types in four bovine muscles, J. Muscle Res. Cell Motil. 15 (1994) 473-486.

[22] Picard B., Gagnière H., Geay Y., Contractile differentiation of bovine masseter muscle, BAM 6 (1996) 316-372.

[23] Robelin J., Picard B., Listrat A., Jurie C., Barboiron C., Pons F., Geay Y., Myosin expression in Semitendinosus muscle during foetal development of cattle: immunocytochemical and electrophoretic analysis, Reprod. Nutr. Dev. 33 (1993) 25-41.

[24] SAS, Stat guide for personal computer, Version 6, SAS Institute Inc., Cary, NC, USA, 1985.

[25] Seedorf U., Leberer E., Kirschbaum B.J., Pette D., Neural control of gene expression in skeletal muscle. Effects of chronic stimulation on lactate dehydrogenase isoenzyme and citrate synthase, Biochem. J. 239 (1986) 115-220.

[26] Suzuki A., A comparative study of the masseter muscle of cattle, sheep, swine, dog, guinea pig and rat, Histochemistry 51 (1977) 121-131.

[27] Thorling E.B., Jensen K., The lactate dehydrogenase isoenzymes in various organs of the rabbit in anemia, hypoxia and after cobalt administration, Acta Pathol. Microbiol. Scand. 66 (1966) $426-436$.

[28] Totland G.K., Kryvi H., Distribution patterns of muscle fibre types in major muscles of the bull (Bos taurus), Anat. Embryol. 184 (1991) $441-450$. 